\title{
CONSTRUÇÃO DE UMA CARTA PARA DETERMINAÇÃO DE ORIENTAÇÃO DE VERTENTES
}

\author{
Manoel Carlos de OLIVEIRA *
}

\begin{abstract}
RESUMO
Este trabalho refere-se ao estudo de um método para construir uma carta de orientação de vertente, através de um gabarito circular.
\end{abstract}

\begin{abstract}
This work deals about a method of carrying out a map of slope direction through a circular abacus.

\section{INTRODUÇÃO}

\section{A IMPORTÂNCIA DE UMA CARTA DE ORIENTAÇÃO DE VERTENTES}

Durante a realização do projeto de plano de manejo do Parque da Capital (Horto Florestal da cidade de São Paulo) surgiu a idéia de se organizar uma carta de orientação de vertentes. A proposta era de confeccionar uma carta que desse condições para se correlacionar com os outros fatores de ordem ambiental para subsidiar a diagnose da área em estudo.

A construção dessa carta dependia de se procurar os meios existentes e que facilitassem sua organização. Chegou até o Autor uma publicação do Instituto de Geografia, DE BIASI et alii (1977) que tratava da confecção e utilização de cartas de orientação de vertentes. Nessa publicação os Autores estudaram os vários métodos e chegaram a propor um, através da construção de um gabarito para determinar a orientação desejada. Apesar do método proposto por DE BIASI et alii (1977) ser bastante eficiente pensou-se em criar um gabarito próprio, para o projeto do Horto Florestal. Esse gabarito deveria ser adequado à carta topográfica que se tinha disponível, e assim foi construído juntamente com a carta de orientação de vertentes.
Antes de se discutir qual a importância de uma carta de orientação de vertentes faz-se necessário alguns comentários sobre o significado de um plano de manejo de parques ou de áreas naturais.

O plano de manejo de parques deve ser atingido através de uma diagnose espacial onde são expressas as aptidões de uso de determinada área. Essa diagnose depende do ponto de interesse natural ou cultural apresentado pela área em questão, ou através do tipo de análise que irá direcionar o plano de manejo. No caso do Horto Florestal os pontos de interesse são clima e vegetação. Nesse projeto era necessário propor como meio de análise para a diagnose, um modelo topográfico, realizado através de mapa e que pudesse ser correlacionado com clima e vegetação. Foi desenvolvido pelo Autor um modelo baseado no sistema de avaliação paramétrica de terreno possuindo por parâmetros: hipsometria, declividade e orientação de vertentes.

Para a correlação com o clima, a orientação de vertentes é um parâmetro muito importante. Ela irá determinar o

\footnotetext{
*Instituto Geológico - Caixa Postal 8772 - 01000 - São Paulo, SP, Brasil.
} 
grau de insolação em decorrência da movimentação do sol durante o dia. Essa correlação é necessária para possibilitar a localização de diversos equipamentos de parques, em função da necessidade de maior ou menor grau insolação desses equipamentos. Quanto à vegetação, sabe-se que determinados povoamentos vegetais estão muito sujeitos à direção climática predominante que é determinada pela exposição topográfica.

\section{MÉTODO DE CONSTRUÇÃO DO GABARITO E DA CARTA DE EXPOSIC̨ÃO DE VERTENTES.}

O mapa base do plano de manejo do Horto Florestal foi organizado através de uma folha topográfica na escala $1: 2.000$. Essa folha foi realizada através de aerolevantamento e restituição aerofotogramétrica, sendo portanto um mapa de alta precisão (INSTITUTO FLORESTAL s.d.). Nessa folha são utilizadas coordenadas métricas do sistema UTM com eqüidistância de $200 \mathrm{~m}$ e as curvas de nível estão representadas a cada metro de desnível. Nesse caso a determinação de orientação de vertente teria que ser de grande precisão não só em decorrência da carta, mas também do trabalho necessário para o plano de manejo.
DE BIASI et alii (1977) descrevem vários métodos para construir gabaritos e cartas de orientação de vertentes, alguns desses métodos são bastante complexos. Discutem ainda que a precisão dessas cartas depende do tipo do gabarito a ser utilizado. O que foi proposto pelos autores, segundo demonstram, conduz a um maior grau de detalhamento e precisão.

O gabarito que está sendo apresentado neste trabalho (Fig. 1) segue em grande parte o princípio indicado por DE BIASI et alii (1977). Foi construído em acetato tipo Kronaflex na forma de um círculo. Nele foram determinadas oito faces de exposição do quadrante. Nessas oito faces foram ainda traçados os eixos centrais que indicam a direção predominante. Outra característica apresentada por este gabarito é quanto ao seu tamanho que corresponde ao das coordenadas métricas do mapa, o que contribui para facilitar seu uso. Através dos eixos X e Y é possível correr o gabarito através das coordenadas métricas e assim localizar a vertente a ter sua orientacão determinada. É necessário antes desse trabalho traçar os eixos das vertentes que correspondem aos topos dos interflúvios. A partir de então é direcionado o gabarito, seu tangenciamento na curva de nível irá indicar a direção da vertente em relação ao quadrante (Fig. 2). 


\section{ÁBACO PARA DETERMINAÇÃO DE ORIENTAÇÃO DE VERTENTE}

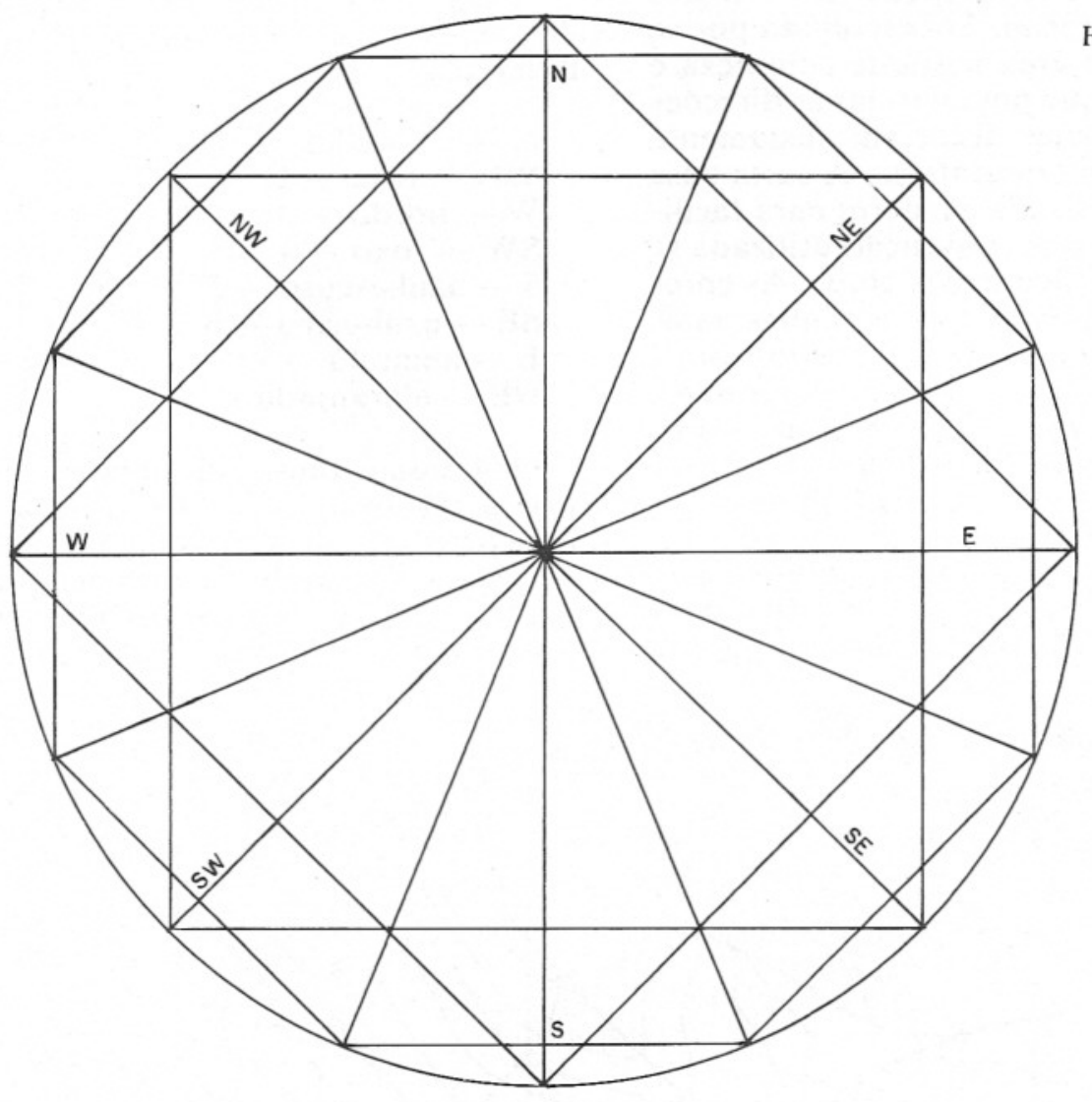

Fig. 1

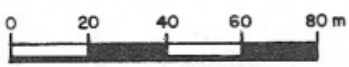

Fig. 2

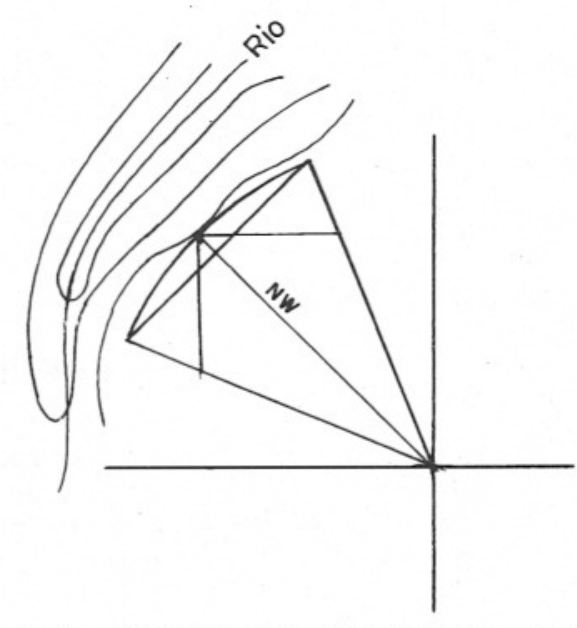




\section{CÓNSIDERAÇÃO SOBRE A CARTA REALIZADA}

A Figura 3 apresenta apenas um trecho na carta de orientação de vertentes do Horto Florestal. Foi escolhida por se tratar de uma área bastante complexa e acidentada e que possui todas as direções de vertentes que decorrem justamente dessas feições topográficas. A carta base inédita foi realizada em cores para facilitar sua análise. A convenção utilizada se baseia na tonalidade das cores. As cores quentes representam as vertentes mais exposias ao sol, assim o vermelho, considerado o tom mais quente corresponde à exposição Norte, enquanto azul, considerada a cor mais fria, corresponde à exposição Sul, que no hemisfério meridional é a de menor insolação.

O mapa de correlação topográfica, construído através do sistema de avaliação paramétrica de terrenos, requer o uso do sistema alfa-númerico; assim, as cores que determina, a exposição das vertentes foram transformadas em número.

A seguir são apresentadas as direções de vertentes com as respectivas cores e números.

$$
\begin{aligned}
& \mathrm{N}-\text { vermelho - } 1 \\
& \mathrm{WN}-\text { rosa - } \\
& \mathrm{W}-\text { bordô-3 } \\
& \mathrm{SW} \text { - roxo - 4 } \\
& \mathrm{S}-\text { azul-escuro }-5 \\
& \mathrm{SE} \text { - azul-claro - } 6 \\
& \mathrm{E}-\text { amarelo - 7 } \\
& \mathrm{NE} \text { - alaranjado - } 8
\end{aligned}
$$

Os terrenos onde a declividade é inferior a $5 \%$ foram considerados na carta base original como áreas planas. Aí a exposição de vertentes à insolação sendo bastante ampla aparece como pertencente ao quadrante Norte.

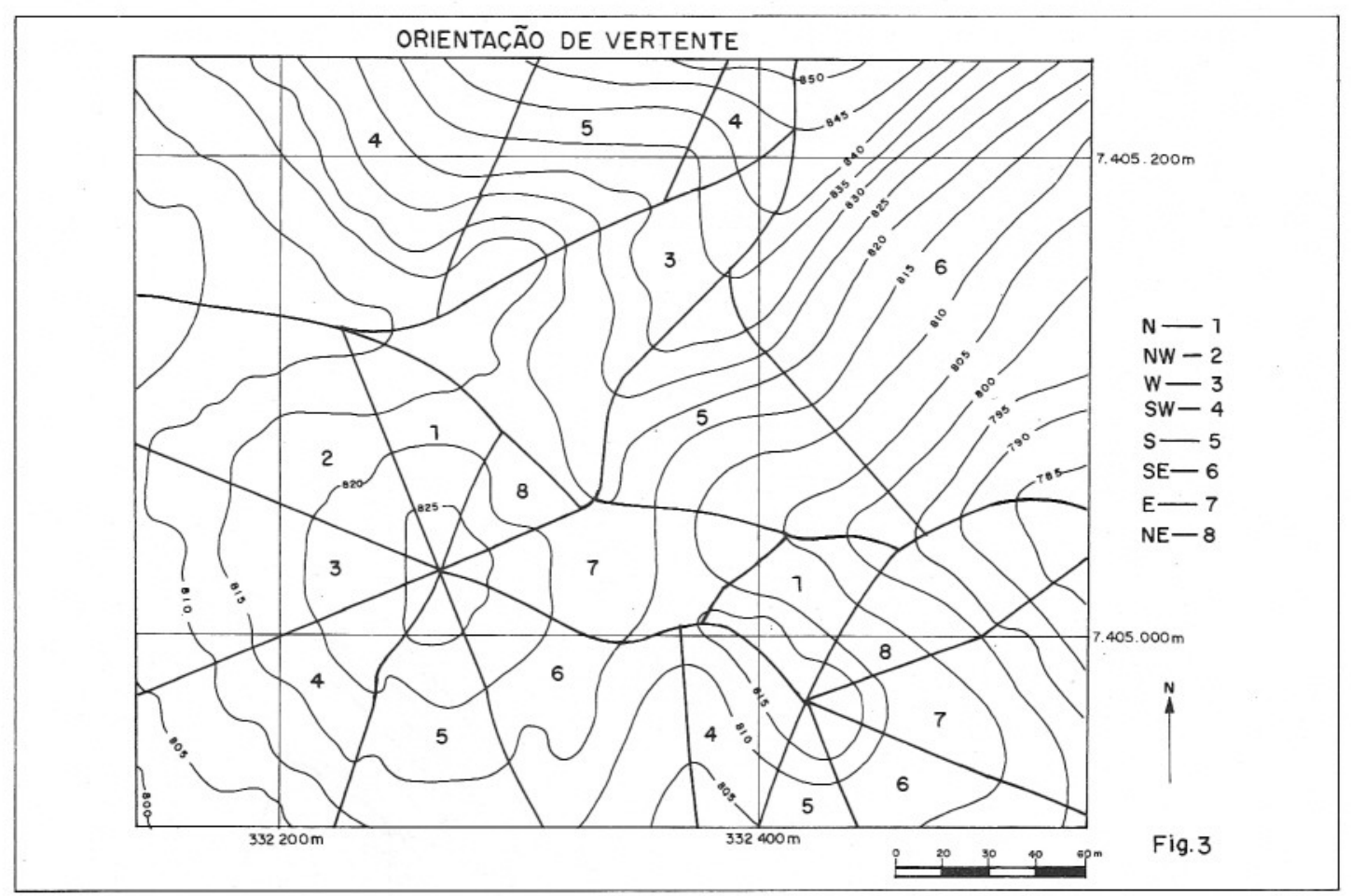

\section{REFERÊNCIAS BIBLIOGRÁFICAS}

DE BIASI, M. et alii 1977 Cartas de orientação de vertentes: confecção e utlização. São Pau1o, Universidade, Instituto de Gengrafia. 12p. (Cartografia, 4).
SÃO PAULO. INSTITUTO FLORESTAL s.d. Perímetro Horto Florestal, São Paulo. São Paulo. Escala 1:2.000 (Cópia fiel do mapa GEGRAN 1:10.000). 